\title{
Avaliação histomorfométrica da combinação de rifamicina com hidroxiapatita sintética na reparação óssea em tíbia de coelhos: um estudo piloto
}

\author{
Histomorphometric evaluation of rifamycin combined with synthetic hydroxyapatite \\ on bone healing in rabbit tibiae: a pilot study
}

\begin{abstract}
Luiz Felipe Palma, ${ }^{1}$ Thalita Caetano Paiva, ${ }^{2}$ Nelson Masanobu Sato, ${ }^{2}$ Lúcio Frigo, ${ }^{2}$ Flávio de Ávila Kfouri ${ }^{2}$
${ }^{1}$ Universidade Federal de São Paulo (Unifesp), Departamento de Diagnóstico por Imagem, Setor de Radioterapia, São Paulo, SP, Brasil

2 Universidade de Mogi das Cruzes (UMC), Mogi das Cruzes, SP, Brasil

- Os autores declaram que não há conflito de interesse.
\end{abstract}

\section{Resumo}

Objetivo: realizar avaliação histomorfométrica da associação do antibiótico rifamicina SV sódica à hidroxiapatita sintética na reparação óssea em tíbia de coelhos. Material e Métodos: doze coelhos brancos machos foram igualmente divididos em Grupo Teste e Controle. Lojas ósseas foram criadas nas tíbias dos animais e preenchidas com hidroxiapatita sintética e solução fisiológica (Grupo Controle) ou associação de hidroxiapatita sintética e rifamicina SV sal sódico (Grupo Teste). Além do mais, sobre todas as perfurações foram fixadas barreiras de politetrafluoretileno expandido. Os animais foram sacrificados após 7,14 ou 21 dias da cirurgia, lâminas para análise em microscópio óptico foram preparadas (coloração H\&E) e as análises realizadas. Resultados: a associação testada demonstrou superioridade no controle microbiológico local, na velocidade de formação e na quantidade final total de deposição de matriz óssea. Conclusão: a combinação de rifamicina com hidroxiapatita sintética parece apresentar vantagens nas condições testadas, incentivando a realização de novos estudos em modelo animal.

Palavras-chave: Tecido ósseo; Hidroxiapatita; Antibacterianos.

\section{ABSTRACT}

Objective: to carry out histomorphometric analysis of the combination of rifamycin SV sodium salt with synthetic hydroxyapatite on bone repair in rabbit tibiae. Material and Methods: twelve male white rabbits were equally divided into a test group and a control group. Drill hole defects were created in the tibiae of the animals and were filled with either synthetic hydroxyapatite and physiological solution (control group) or a combination of synthetic hydroxyapatite and rifamycin (test group). Moreover, all defects were covered by expanded polytetrafluoroethylene barriers. The animals were euthanized at on day 7, 14, or 21. The tissue sections were mounted onto slides (H\&E staining) and were analysed using an optical microscope. Results: the tested association presented better microbiological local control, faster bone matrix deposition rate, and higher final total amount of bone matrix deposition. Conclusion: the combination of rifamycin with synthetic hydroxyapatite seems to be advantageous under the tested conditions, encouraging the development of new animal model studies.

Keywords: Bone tissue; Hydroxyapatite; Antibacterials.

\section{Introdução}

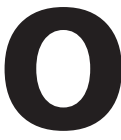
$s$ conceitos em que se baseia o uso dos enxertos ósseos em cirurgia oral e maxilofacial são: osteogênese, osteoindução e osteocondução. ${ }^{1}$ Entre as mais diversas técnicas com esta finalidade, a utilização de tecido autógeno é considerada mundialmente como o padrão-ouro, por apresentar as três características simultaneamente, ${ }^{2-4}$ não causar reações imunológicas, não transmitir doenças e ser mais econômica. ${ }^{5}$ Apesar disso, inúmeros substitutos ósseos vêm sendo buscados e desenvolvidos, ${ }^{1,6}$ uma vez que já é bem conhecido que enxertos autógenos apresentam maiores taxas de remodelação, dependendo de fatores como arranjo estrutural, vascularização e estabilização. ${ }^{7}$ Limitada quantidade de material disponível para coleta, necessidade de um sítio cirúrgico adicional e consequente morbidade e maiores tempos cirúrgicos e anestésicos são outras desvantagens da técnica. ${ }^{2,3}$

Três grandes grupos de materiais alternativos podem ser também encontrados para uso clínico: aloenxertos (doação entre indivíduos da mesma espécie), xenoenxertos (doação entre espécies) e materiais aloplásticos (sinteticamente produzidos). ${ }^{4}$ Estes últimos são principalmente compostos pelos cristais de hidroxiapatita ou outros minerais de fosfato de cálcio, análogos aos presentes no tecido ósseo e que favorecem o processo de osteocondução pela criação de arcabouço ou substrato favorável no qual os osteoblastos possam depositar gradualmente um novo tecido osteoide. Ademais, já foram demonstradas a similaridade estrutural entre a hidroxiapatita sintética e a orgânica, confirmando excelente biocompatibilidade, ${ }^{3,6} \mathrm{e}$ as fortes e indistinguíveis ligações químicas geradas quando o material é enxertado em defeitos ósseos. ${ }^{8}$

Independentemente do tecido ou material de enxertia, o cirurgião oral e maxilofacial enfrenta o problema de atuar em uma região altamente contaminada, mesmo tomando todas as medidas cabíveis e recomendadas. É muito comum que os enxertos ósseos toquem regiões da 
cavidade oral e se contaminem com saliva, além de, eventualmente, algumas pequenas intercorrências ocorrerem com as superfícies não estéreis do ambiente. ${ }^{7,9}$ Estas eventuais contaminações, que estão associadas com infecções e que podem comprometer o resultado dos enxertos, já foram investigadas e alguns agentes químicos e soluções antibióticas demonstraram satisfatória atividade de descontaminação com preservação das características regenerativas desejáveis. ${ }^{7}$

Recentemente, a associação de outros compostos e substâncias nos enxertos ósseos, como a fibrina rica em plaquetas $^{4}$ ou o plasma rico em plaquetas e alguns antibióticos, vem sendo proposta para prevenir infecções na área de interesse e promover otimização do reparo tecidual. ${ }^{1}$ Entretanto, alguns autores sugerem atitudes mais extremas, como até profilaxia antibiótica ${ }^{5}$ e antibioticoterapia pós-cirúrgica por períodos significativos.

Entre todas estas substâncias já avaliadas para o controle microbiológico local dos enxertos, estão as rifamicinas, antibióticos macrolídeos semissintéticos derivados da natural rifamicina $\mathrm{B}$. Possuem largo espectro de atividade bactericida contra micro-organismos gram-positivos e negativos, sendo bastante utilizadas no tratamento de feridas cutâneas cirúrgicas e traumáticas, ${ }^{1}$ além de bem toleradas. ${ }^{7}$ No entanto, pouca informação ainda é disponibilizada a respeito destas substâncias associadas a enxertos ósseos em cirurgia oral e maxilofacial, devendo investigar-se melhor o real potencial de descontaminação, as influências no processo de reparação e regeneração óssea, a liberação local de fatores de crescimento, ${ }^{7}$ a toxicidade ${ }^{4}$ e o tempo de exposição. ${ }^{10}$

Desta forma, o objetivo do presente estudo piloto é realizar avaliação histomorfométrica da associação do antibiótico rifamicina à hidroxiapatita sintética na reparação óssea em tíbia de coelhos.

\section{Material e Métodos \\ - Informações Gerais e Aspectos Éticos}

Realizou-se estudo experimental, prospectivo, nas instalações laboratoriais da Universidade de Mogi das Cruzes (UMC), São Paulo/Brasil. Foi obtida aprovação do Comitê de Ética em Pesquisa com Uso de Animais da mesma instituição previamente à realização de qualquer procedimento aqui descrito (Protocolo 004/2012).

\section{- Seleção, Classificação e Manejo da Amostra}

Foram utilizados doze coelhos brancos machos saudáveis, linhagem Nova Zelândia, com idade entre quatro meses a um ano e peso de aproximadamente $2,5 \mathrm{~kg}$. Cada animal foi mantido em gaiola individual, com higienização e alimentação idênticas realizadas pelo técnico do Biotério Central da mesma instituição.
Aleatoriamente, os animais foram distribuídos em Grupo Controle e Grupo Teste, com seis animais cada um. Cada grupo foi novamente dividido ao acaso, contabilizando mais três subgrupos de dois animais cada, de acordo com os períodos de avaliação posteriormente analisados (7, 14, 21 dias).

\section{- Procedimentos Pré, Trans e Pós-cirúrgicos}

Todos os animais foram submetidos à intervenção cirúrgica idêntica, sob as mesmas condições, além de 12 horas de jejum de ração e água.

Inicialmente, foram administradas substâncias pré -anestésicas, tranquilizantes, potencializadoras e anestésicas: acepromazina $(0,75 \mathrm{mg} / \mathrm{kg})$, cloridrato de xilazina ( $5 \mathrm{mg} / \mathrm{kg}$ ) e cloridrato de ketamina $(35 \mathrm{mg} / \mathrm{kg})$.

As áreas a serem operadas passaram por processo de tricotomização e foram submetidas à antissepsia local com solução de clorexidina a $2 \%$. Campos cirúrgicos estéreis isolaram as regiões das tíbias onde foram realizados os procedimentos. Os coelhos foram posicionados na mesa operatória em decúbito dorsal e com rotação cervical lateral direita, mantendo livres as vias aéreas (Figura 1).

As incisões nas tíbias foram realizadas com lâmina de bisturi número 15, iniciaram-se logo abaixo da articulação do joelho e estenderam-se por $30 \mathrm{~mm}$ de comprimento. Com um descolador de Molt afastou-se a pele, músculos e periósteo, expondo o osso do animal (Figura 1).

Uma loja cirúrgica foi criada em cada tíbia do mesmo animal e sempre pelo mesmo cirurgião, utilizando fresas com irrigação constante de solução fisiológica estéril e em motor cirúrgico elétrico configurado em $1200 \mathrm{rpm}$ e conectado a um contra-ângulo com redução de rotações na razão 16:1. Cada nicho deveria apresentar padrão de 4 $\mathrm{mm}$ de profundidade e $3 \mathrm{~mm}$ de diâmetro (Figura 1).

O Grupo Controle teve preenchimento dos defeitos com mistura de hidroxiapatita sintética $\left(\right.$ Osteogen $\left.^{\circledast}\right)$ e solução fisiológica; já o Grupo Teste recebeu associação de hidroxiapatita sintética $\left(\right.$ Osteogen $\left.^{\circledast}\right)$ e rifamicina SV sal sódico $10 \mathrm{mg} / \mathrm{mL}$ (Rifocina ${ }^{\circledast}$ ), esta apenas na quantidade suficiente para umedecer o enxerto e torná-lo manipulável. Além do mais, sobre todas as perfurações foram fixadas barreiras de politetrafluoretileno expandido (PTFE -e), por meio de tachinhas metálicas.

Finalmente, o periósteo e os tecidos moles dos animais foram suturados com fio mononylon 4.0 (Figura 1). Como cuidados pós-operatórios, em período de três a quatro dias, foram utilizados o anti-inflamatório flunixina $(1,1$ $\mathrm{mg} / \mathrm{kg}$ ) de 12 em 12 horas e um spray antimordida. 

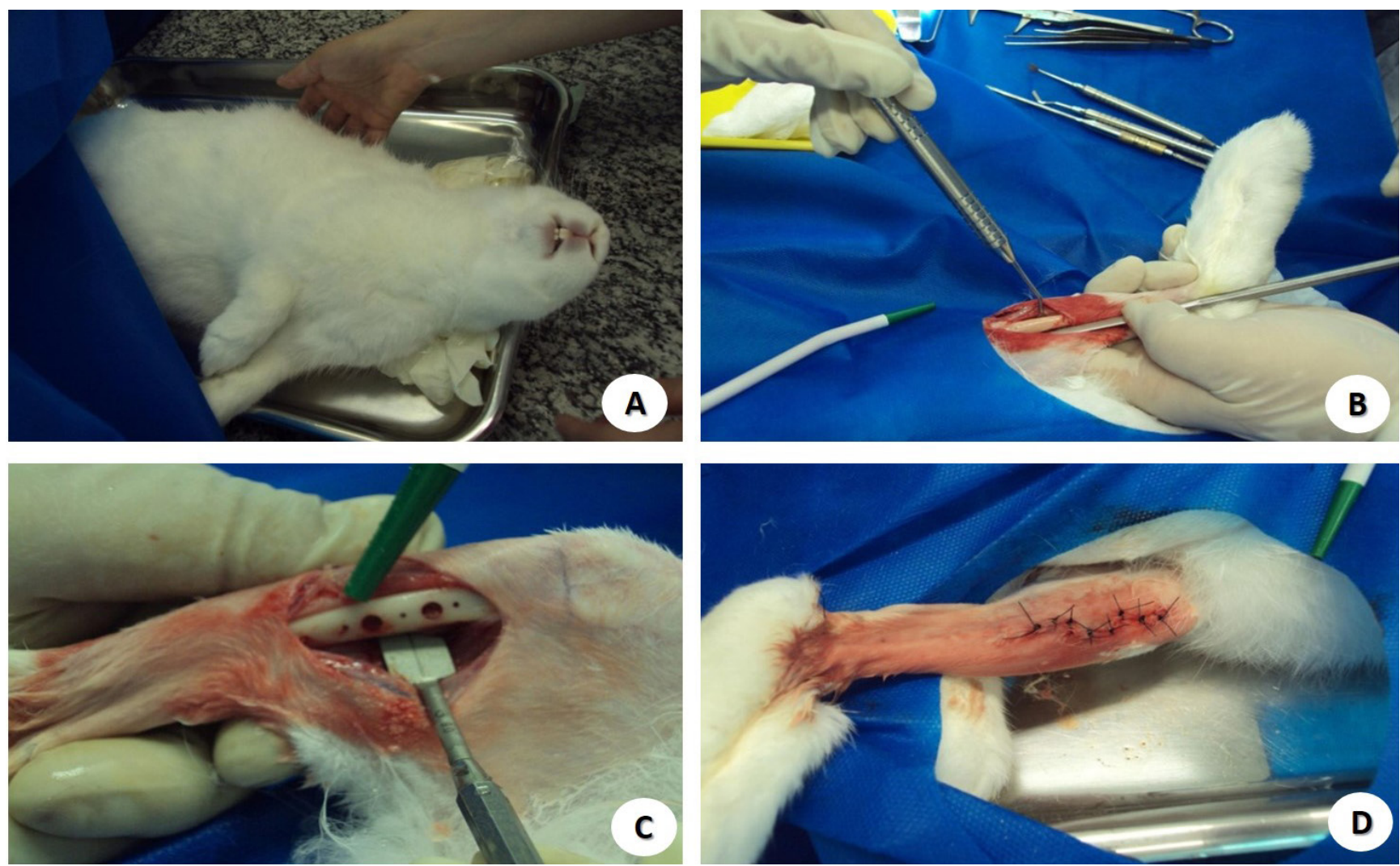

Figura 1. Experimento. Em " $A$ " posição do coelho para realização da cirurgia. " $B$ " afastamento dos tecidos moles para exposição óssea. Já em " $C$ " criação da loja cirúrgica e " $D$ " a sutura

\section{- Eutanásia dos Animais e Coleta de Material}

De acordo com o subgrupo que cada animal pertencia, após 7, 14 e 21 dias da realização das cirurgias, efetuou-se eutanásia pela aplicação de cloridrato de cetamina $(35 \mathrm{mg} /$ $\mathrm{kg}$ ) e $0,3 \mathrm{ml} / \mathrm{kg}$ de $T-61^{\oplus}$.

Feito isso, as amostras foram removidas para análise histológica com novo procedimento cirúrgico semelhante ao anterior, porém com auxílio de serra cirúrgica. As tíbias foram seccionadas com $3 \mathrm{~mm}$ de margem de segurança em relação às paredes laterais vizinhas aos enxertos.

\section{- Armazenamento, Preparo e Análise de Material}

Cada material coletado foi imediatamente inserido em frasco de vidro cor âmbar, contendo formol a 10\%, e devidamente identificados. $\mathrm{Na}$ sequência, foram desidratados em banhos de álcool em ordem crescente, descalcificados em ácido sulfúrico, incluídos em parafina e cortados em micrótomo com espessura de $4 \mu \mathrm{m}$. Em seguida, os cortes histológicos foram preparados em lâminas e submetidos à coloração por hematoxilina e eosina (H\&E).

Sempre pelo mesmo pesquisador, a análise de todas as lâminas histológicas foi realizada por meio de microscópio óptico com diferentes objetivas (10x e 40x), atentando-se para erros de técnica e aspectos e tipos celulares presentes.

Nas coletas de 7 dias após a cirurgia, a quantificação celular de neutrófilos foi realizada com finalidade de observar controle local de presença microbiana. Nas de 14 dias, foram avaliadas características do início de deposição de matriz óssea e células ósseas; já nas de 21 dias, foram feitas análises médias de neoformação óssea, com auxílio do software

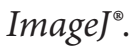

\section{Resultados}

\section{- Material de 7 Dias Após a Cirurgia}

No material coletado de ambos os grupos notou-se a presença de neutrófilos, porém o Grupo Teste possuiu menores quantidades de maneira geral. A tabela 1 demonstra os valores totais destas células nas áreas de contagens em que as lâminas foram divididas.

Tabela 1. Contagem de neutrófilos do material proveniente de ambos os grupos após 7 dias da cirurgia

\begin{tabular}{c|c|c}
\hline \multicolumn{3}{c}{ Número de neutrófilos } \\
\hline Áreas de contagem & Grupo Controle & Grupo Teste \\
\hline I & 8 & 11 \\
\hline II & 25 & 11 \\
\hline III & 12 & 19 \\
\hline IV & 7 & 3 \\
\hline $\mathrm{V}$ & 9 & 9 \\
\hline $\mathrm{VI}$ & 21 & 16 \\
\hline Total de células & 82 & 69 \\
\hline
\end{tabular}


As Figuras 2 e 3 retratam bem o padrão observado nas amostras do Grupo Controle e Teste, em diferentes objetivas.

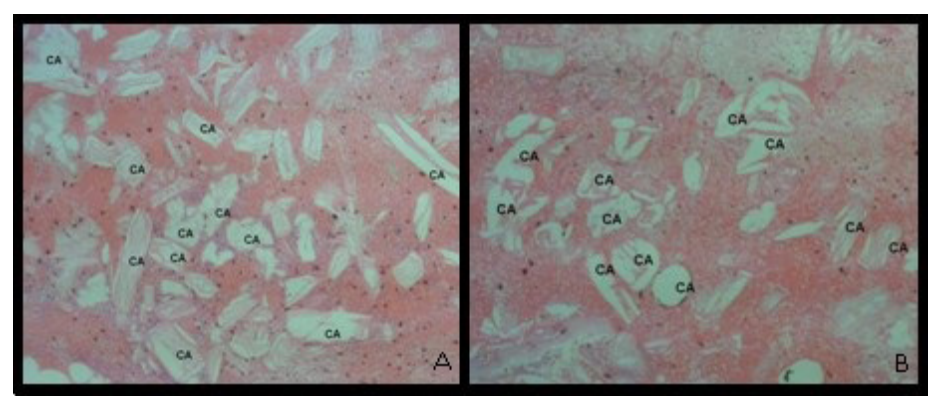

Figura 2. Análises provenientes do Grupo Controle (A) e Grupo Teste (B). Cristais de hidroxiapatita (CA). Aumento de 10x, coloração H\&E

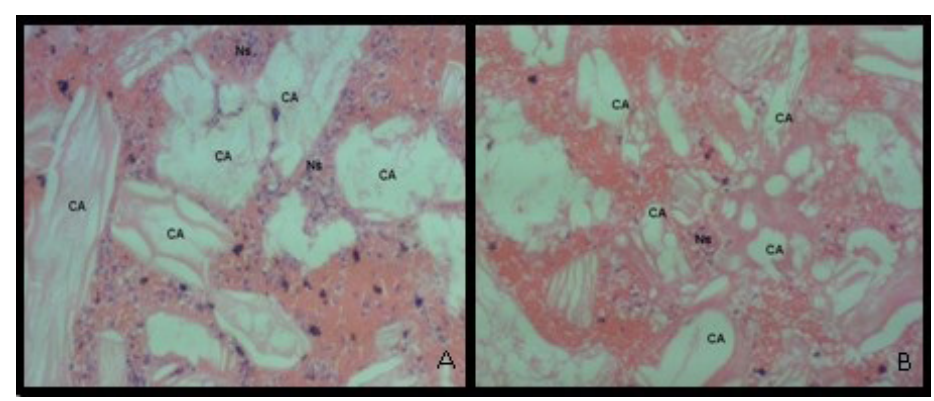

Figura 3. Análises provenientes do Grupo Controle (A) e Grupo Teste (B). Cristais de hidroxiapatita (CA) e neutrófilos (Ns). Aumento de 40x, coloração H\&E

\section{- Material de 14 Dias Após a Cirurgia}

No material coletado de ambos os grupos notou-se grande presença de osteoclastos e osteoblastos, porém, diferentemente, o Grupo Teste demonstrou recente formação de matriz óssea. Além do mais, as lâminas do Grupo Teste apresentaram menor campo de visão das perfurações, ou seja, houve deposição de nova matriz óssea de forma centrípeta. Nas lâminas do Grupo Controle, ainda foi possível visualizar lacunas entre o tecido ósseo vital e as perfurações.

As Figuras 4 e 5 retratam bem o padrão observado nas amostras do Grupo Controle e Teste, em diferentes objetivas.

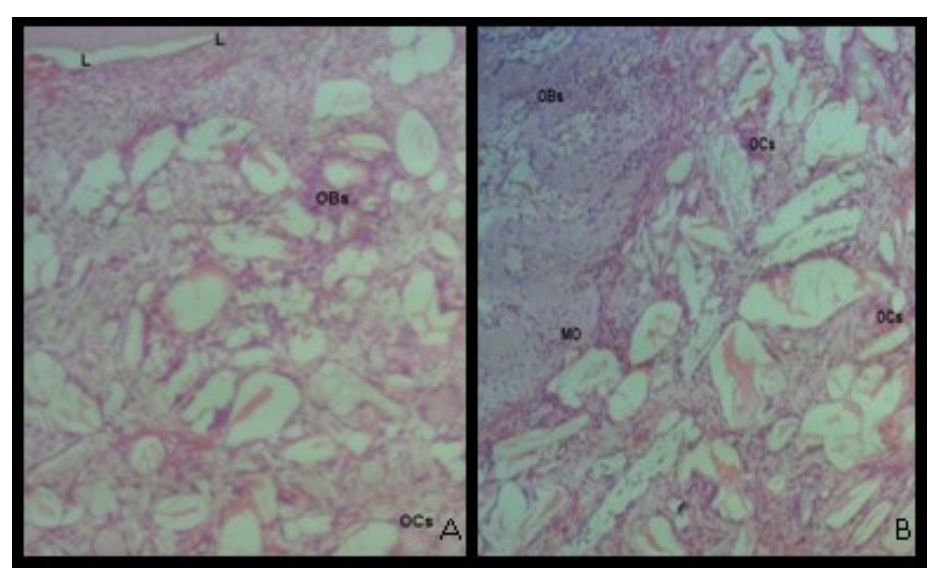

Figura 4. Análises provenientes do Grupo Controle (A) e Grupo Teste (B). Lacuna entre osso vital e material de enxerto (L) e matriz óssea (MO). Osteoblastos (OBs) e osteoclastos (OCs). Aumento de 10x, coloração H\&E

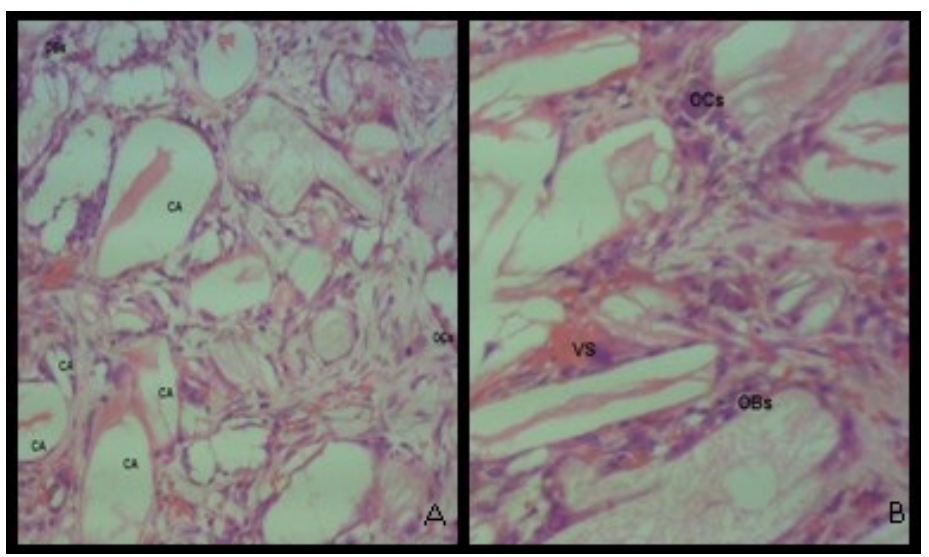

Figura 5. Análises provenientes do Grupo Controle (A) e Grupo Teste (B) Osteoblastos (OBs), osteoclastos (OCs), vaso sanguíneo (VS) e cristais de hidroxiapatita (CA). Aumento de $40 x$, coloração H\&E

\section{- Material de 21 Dias Após a Cirurgia}

No material coletado em ambos os grupos notou-se a presença de nova matriz óssea bem organizada e com vasos sanguíneos. Osteoclastos e osteoblastos foram ainda encontrados em todas as análises.

Em relação ao volume de deposição de nova matriz óssea, os materiais obtidos no Grupo Teste demonstraram valores mais elevados, como mostrado na Figura 6.

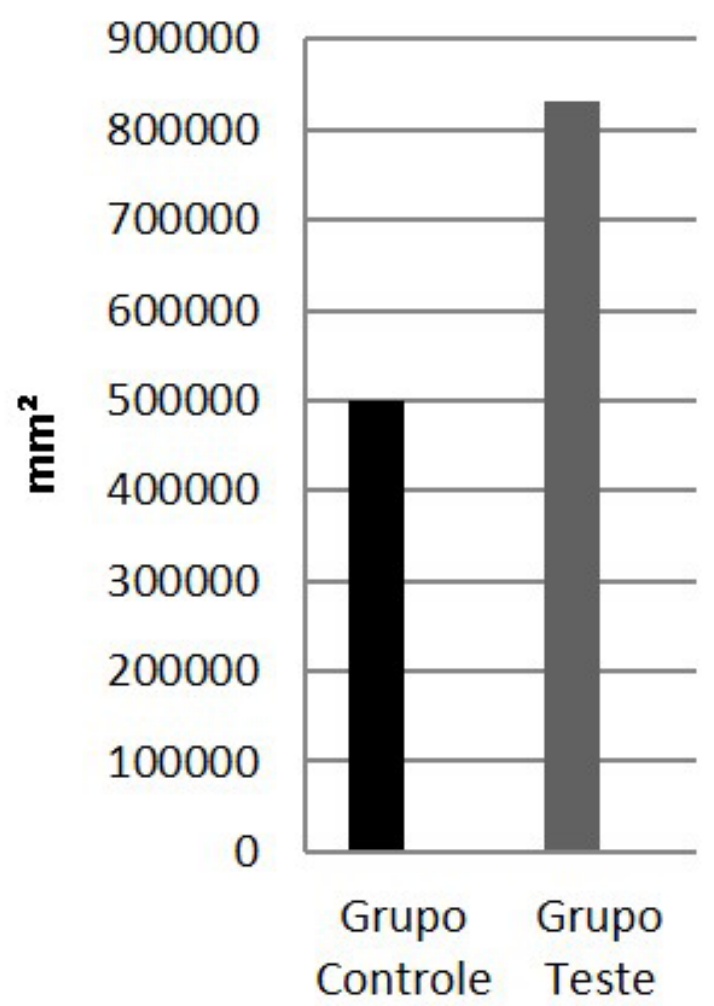

Figura 6. Área de deposição de nova matriz óssea. Medidas das áreas de deposição de nova matriz óssea do material proveniente de ambos os grupos após 21 dias da cirurgia, em $\mathrm{mm}^{2}$

Rev. Bras. Odontol., Rio de Janeiro, v. 74, n. 2, p. 82-7, abr./jun. 2017 


\section{Discussão}

Diversos estudos já buscaram investigar os efeitos da combinação de agentes antibióticos com diferentes materiais de enxertia. Estas associações são baseadas no conceito de que a vascularização em sítios recém-enxertados é extremamente pobre, tornando difícil a penetração e ação terapêutica de antibióticos administrados sistemicamente. Assim, os agentes antimicrobianos aplicados junto com os enxertos poderiam minimizar os riscos de infecção inicial, diminuindo efeitos adversos e toxicidade de altas doses de antibióticos sistêmicos que seriam necessários. ${ }^{7}$

A rifamicina, bastante utilizada em cirurgia oral e maxilofacial, foi a substância de eleição para o presente estudo, já que é rara a ocorrência de efeitos adversos. É importante salientar, entretanto, que alguns poucos casos de reações anafiláticas já foram reportadas na literatura ${ }^{11-13}$ e merecem atenção do clínico.

Yaman et al. ${ }^{9}$ avaliaram o efeito de algumas substâncias na eliminação de micro-organismos patogênicos (Staphylococcus aureus, Pseudomonas aeruginosa e Escherichia coli) inoculados em tecido ósseo removido de fêmures de ratos. A iodopovidona, a neomicina, a cefazolina sódica e a rifamicina foram descontaminantes efetivos e não apresentaram danos estruturais ao osso. A rifamicina foi a única capaz de eliminar todos os micro-organismos testados, sendo, então, sugerida como a mais apropriada para eliminação de contaminações durante cirurgias de enxertos.

Nossos dados, provenientes das amostras de 7 dias, demonstraram que o Grupo Teste possivelmente se beneficiou do efeito da rifamicina, ilustrado pela menor quantidade de neutrófilos presentes nas lâminas. Estas células dendríticas não apresentam antígenos para linfócitos, fazendo parte da resposta imune inata e aparecendo como linha de frente ao combate de micro-organismos infecciosos.

As evidências de efeitos aceleradores do processo de reparação óssea quando se associam enxertos e agentes an- timicrobianos ainda são insuficientes e controversas. Simsek et al. ${ }^{4}$ investigaram, também em coelhos, a combinação de aloenxerto com fibrina rica em plaquetas ou rifamicina para preenchimento de defeitos peri-implantares. Após 4 semanas, foram avaliados contato osso-implante (BIC) e porcentagem de neoformação óssea e ambas as associações apresentaram resultados superiores em comparação ao grupo controle. Tasdemir et al. ${ }^{7}$ avaliaram, em ratos, o efeito da rifamicina em enxertos autógenos (onlay) contaminados com saliva e fixados em mandíbula. Ficou concluído que a rifamicina não apresentou efeito prejudicial ao volume ósseo enxertado, contagem de células ósseas ou vascularização da região. Além do mais, curiosamente, o uso da substância aumentou o número de osteoblastos e proteína morfogenética óssea-2. No presente estudo, foi possível evidenciar nos materiais provenientes de 14 e 21 dias que o Grupo Teste apresentou precoce deposição de matriz óssea, além de maior área total final.

Em contrapartida aos indícios favoráveis a esta aplicação da rifamicina, Kaya et al. ${ }^{1}$ avaliaram histologicamente, em tíbias de ratos e após 21 dias da cirurgia, diferentes tipos de enxertos em associação ou não à rifamicina. Reportaram que o antibiótico acelerou o processo de reparo ósseo apenas em sítios em que nenhum material de enxerto foi utilizado. Adicionalmente, os nichos preenchidos com rifamicina e aloenxerto tiveram neoformação óssea reduzida.

\section{Conclusão}

Foram obtidas evidências positivas que fundamentam a associação clínica do enxerto de hidroxiapatita sintética com a rifamicina. Acreditamos que os resultados reportados neste estudo piloto possam direcionar e incentivar novas pesquisas em modelo animal, com maiores amostra e período de seguimento, outros materiais de enxertia e agentes antimicrobianos e diferentes tipos de métodos de avaliação.

\section{Referências}

1. Kaya A, Kaya B, Aktas A, Firat ET. Effect of rifampin in combination with allogeneic, alloplastic, and heterogenous bone grafts on bone regeneration in rat tibial bone defects. J Oral Maxillofac Surg Med Pathol. 2015;27(1):20-8.

2. Tezulas E, Dilek OC, Topcuoglu N, Kulekci G. Decontamination of autogenous bone grafts collected during dental implant site preparation: a pilot study. Oral Surg Oral Med Oral Pathol Oral Radiol Endod. 2009;107(5):656-60.

3. Dutta SR, Passi D, Singh P, Bhuibhar A. Ceramic and non-ceramic hydroxyapatite as a bone graft material: a brief review. Ir J Med Sci. 2015;184(1):101-6.

4. Şimşek S, Özeç İ, Kürkçü M, Benlidayı E. Histomorphometric Evaluation of Bone Formation in Peri-Implant Defects Treated With Different Regeneration Techniques: An Experimental Study in a Rabbit Model. J Oral Maxillofac Surg. 2016;74(9):1757-64.

5. Tezulas E, Dilek OC. Decontamination of autogenous bone grafts collected from dental implant sites via osteotomy: a review. Oral Surg Oral Med Oral Pathol Oral Radiol Endod. 2008;106(5):679-84.

6. Kattimani VS, Chakravarthi SP, Neelima Devi KN, Sridhar MS, Prasad LK. Comparative evaluation of bovine derived hydroxyapatite and synthetic hydroxyapatite graft in bone regeneration of human maxillary cystic defects: a clinico-radiological study. Indian J Dent Res. 2014;25(5):594-601.

7. Taşdemir U, Özeç İ, Esen HH, Avunduk MC. The influence of rifamycin decontamination on incorporation of autologous onlay bone grafts in rats: A histometric and immunohistochemical evaluation. Arch Oral Biol. 2015;60(5):724-9. 8. Jayaswal GP, Dange SP, Khalikar AN. Bioceramic in dental implants: A review. J Indian Prosthodont Soc. 2010;10(1):8-12.

9. Yaman F, Unlü G, Atilgan S, Celik Y, Ozekinci T, Yaldiz M. Microbiologic and histologic assessment of intentional bacterial contamination of bone grafts. J Oral Maxillofac Surg. 2007;65(8):1490-4.

10. Verdugo F, Sáez-Rosón A, Uribarri A, Martínez-Conde R, Cabezas-Olcoz J, Moragues MD, et al. Bone microbial decontamination agents in osseous grafting: an in vitro study with fresh human explants. J Periodontol. 2011;82(6):863-71.

11. Cardot E, Tillie-Leblond I, Jeannin P, Facon A, Breuil K, Patte F, et al. Anaphylactic reaction to local administration of rifamycin SV. J Allergy Clin Immunol. 1995;95(1 Pt 1):1-7.

12. Erel F, Karaayvaz M, Deveci M, Ozangüç N. Severe anaphylaxis from rifamycin SV. Ann Allergy Asthma Immunol. 1998;81(3):257-60.

13. Ebo DG, Verheecke G, Bridts CH, Mertens CH, Stevens WJ. Perioperative anaphylaxis from locally applied rifamycin SV and latex. Br J Anaesth. 2006;96(6):738-41. 


\section{Mini Currículo e Contribuição dos Autores}

1. Luiz Felipe Palma - cirurgião-dentista e PhD. Contribuição: participação científica e intelectual efetiva para o estudo; interpretação dos dados; análise estatística; preparação do manuscrito; redação do manuscrito; revisão crítica e aprovação final.

2. Thalita Caetano Paiva - farmacêutica. Contribuição: participação científica e intelectual efetiva para o estudo; concepção e delineamento; aquisição dos dados; procedimentos técnicos; exames macroscópicos e histopatológicos e aprovação final.

3. Nelson Masanobu Sato - cirurgião-dentista. Contribuição: participação científica e intelectual efetiva para o estudo; procedimentos técnicos e aprovação final.

4. Lúcio Frigo - cirurgião-dentista e PhD. Contribuição: participação científica e intelectual efetiva para o estudo; concepção e delineamento; aquisição dos dados; interpretação dos dados; exames macroscópicos e histopatológicos e aprovação final.

5. Flávio de Ávila Kfouri - cirurgião-dentista e PhD. Contribuição: participação científica e intelectual efetiva para o estudo; concepção e delineamento; interpretação dos dados; procedimentos técnicos; redação do manuscrito; revisão crítica e aprovação final.

Recebido em: 08/01/2017 / Aprovado em: 08/03/2017

Autor Correspondente

Luiz Felipe Palma

E-mail: luizfelipep@hotmail.com 